\title{
Commentary: Advancing the ongoing great cardioplegia debate
}

Daniel J. P. Burns, MD, MPhil

\author{
From the Department of Thoracic and Cardiovascular Surgery, Cleveland Clinic Foundation, Cleveland, Ohio. \\ Disclosures: Author has nothing to disclose with regard to commercial support. \\ Received for publication July 21, 2019; accepted for publication July 22, 2019; available ahead of print Sept 10, \\ 2019. \\ Address for reprints: Daniel J. P. Burns, MD, MPhil, Department of Thoracic and Cardiovascular Surgery, Cleve- \\ land Clinic, 9500 Euclid Ave, J4-133, Cleveland, OH 44195 (E-mail: burnsd@ccf.org). \\ J Thorac Cardiovasc Surg 2019;158:1555-6 \\ 0022-5223/\$36.00 \\ Copyright (C) 2019 by The American Association for Thoracic Surgery \\ https://doi.org/10.1016/j.jtcvs.2019.07.065
}

Despite extensive research on the topic, the issue of myocardial protection methodology remains unresolved and is largely a matter of surgeon preference and comfort. As new solutions have become more prominent, they have failed to demonstrate a clear clinical advantage or detriment when studied. ${ }^{1,2}$ An issue of paramount importance in cardiac surgery, new cardioplegia solutions require rigorous testing to ensure safety and clinical efficacy. Santer and colleagues ${ }^{3}$ attempt just this with a novel polarizing cardioplegia solution, St Thomas' Hospital polarized cardioplegia (STH-Pol-B).

Conventional St Thomas' Hospital solution (STH2) relies on depolarizing hyperkalemic and hypermagnesemic arrest. Noting drawbacks of this method, Santer and colleagues $^{3}$ hypothesized that a novel polarizing solution containing esmolol, adenosine, and magnesium gluconate (ie, STH-Pol-B) would be noninferior to the conventional STH2 solution. This was tested in a pig model using 13 animals. The primary end point was creatine kinasemuscle/brain release at multiple time points during 60 minutes of on-pump and a subsequent 90 minutes of off-pump reperfusion, following a 60-minute ischemic time. In addition, there were multiple secondary end points in histology, hemodynamic parameters, and myocardial micro-RNA expression. To account for the repeated measures aspect of the methodology, a linear mixed-effect model was applied. After analysis, creatine kinase-muscle/brain and troponin-I levels were found not statistically different between the cardioplegia groups, although several secondary end points favored the novel STH-Pol-B group.

Interpretation of a basic science study of this nature is always challenging. One issue is the that healthy animal hearts were arrested, but not stressed further in terms of a surgical insult. The additional 60 minutes of on-pump reperfusion also presents a departure from the norm in cardiac surgery, calling into question how well the model approximates the real world. The Authors have ultimately

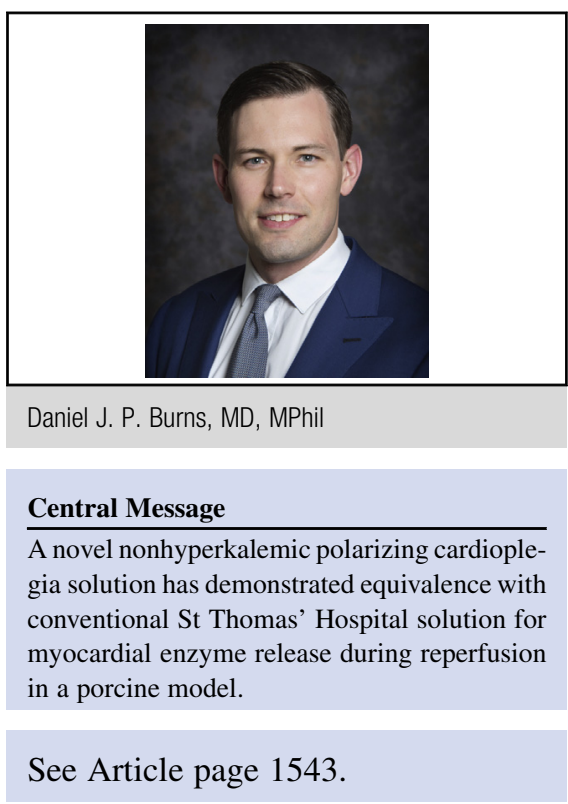

concluded that the novel solution (ie, STH-Pol-B) is noninferior to the conventional STH2, with some potential benefits observed. The problem with this is that there is a noninferiority hypothesis without a noninferiority study design. ${ }^{4}$ Furthermore, the potential benefits demonstrated are in secondary end points, of which there are several, and for which this study was not powered. The issues of multiple testing, sample size, and subsequent spurious results are present. Although the study had an adequate sample size for $80 \%$ power to detect a 5-unit difference (minimum 6 pigs per group) based on a previous rat model, ${ }^{3,5}$ with a small population the problem of random sampling error exists, even if baseline animal characteristics are similar. For these reasons secondary end points favoring the experimental STH-Pol-B group must be considered, at best, hypothesis-generating.

Where does this leave us clinically? The results should be considered encouraging in that the novel solution did not appear to perform poorer than the conventional solution. There is certainly a focus for future research here, with STH-Pol-B being tested in additional models and perhaps, ultimately, humans. Despite the limitations, this can certainly be seen as a necessary incremental step forward in the quest to provide a more perfect method of myocardial protection. 


\section{References}

1. Li Y, Lin H, Zhao Y, Li Z, Liu D, Wu X, et al. Del Nido cardioplegia for myocardial protection in adult cardiac surgery: a systematic review and meta-analysis. ASAIO J. 2018;64:360-7.

2. Edelman JJ, Seco M, Dunne B, Matzelle SJ, Murphy M, Joshi P, et al. Custodiol for myocardial protection and preservation: a systematic review. Ann Cardiothorac Surg. 2013;2:717-28.
3. Santer D, Kramer A, Kiss A, Aumayr K, Hackl M, Heber S, et al. St Thomas' Hospital polarizing blood cardioplegia improves hemodynamic recovery in a porcine model of cardiopulmonary bypass. J Thorac Cardiovasc Surg. 2019;158:1543-54.e8.

4. Juneja A, Aggarwal AR, Adhikari T, Pandey A. Testing of hypothesis in equivalence and non-inferiority trials - a concept. J Clin Diagn Res. 2016;10:LG01-3.

5. Fujii M, Chambers DJ. Cardioprotection with esmolol cardioplegia: efficacy as a blood-based solution. Eur J Cardiothorac Surg. 2013;43:619-27. 